\title{
RANCANG BANGUN SISTEM MEKANIK SPEEDBUMP GENERASI KE 3 SEBAGAI PENGHASIL DAYA LISTRIK
}

\author{
Armanda Putra Rilda Lubis, Prof. Dr. Ir. Bustami syam,MSME \\ Departmen Teknik Mesin, Fakultas Teknik, Universitas Sumatra Utara \\ Jl. Politeknik, Padang Bulan, Kec. Medan Baru, Kota Medan,Sumatra Utara 20222 \\ Email: armandaputra28@yahoo.com
}

\begin{abstract}
ABSTRAK
Speed bump atau di indonesia dikenal sebagai polisi tidur yang berfungsi untuk mengurangi kecepatan kendaraan. Pada penelitian ini speed bump di rancang dan dibangun sebagai pembangkit energi listrik. Sistem mekanik dari rancang bangun speed bump ini terdiri dari pegas, sprocket, rantai, poros, bantalan, flywheel, dan kumparan magnet. Ketika kendaraan menekan speed bump, sistem mekanisme mulai bekerja, pegas yang dihubungkan langsung pada speed bump terhubung juga pada poros penggerak dengan menggunakan tali kawat. Kemudian roda penggerak tersebut dihubungkan dengan sproket yang dipasang antara roda penggerak, sproket tersebut akan memutar flywheel, putaran yang diterima flywheel tersebut akan diteruskan untuk memutar generator untuk menghasilkan energi listrik. Untuk merancang sistem mekanik, masing-masing komponen dihitung keukatan, tegangan, kecepatan serta ketahanannya, antara lain nilai tegangan pegas adalah $248.6 \mathrm{Kpsi}$, sprocket besar dengan diameter $140 \mathrm{~mm}$, sprocket kecil dengan diameter $50 \mathrm{~mm}$, kekuatan putus rantai sebesar $3816 \mathrm{~N}$. Dan untuk sistem mekanik secara keseluruhan digambar dengan menggunakan Auto CAD.
\end{abstract}

Kata Kunci: Sistem mekanik, generator, Speed Bump

\begin{abstract}
Speed bump in Indonesia also known as polisi tidur and have a function to reduce velocity of vechile, in this research speed bump is designed and builded that also have function to generate electricity, mechanic system from this design are springs, sprocket, roller chain, shaft, bearing, flywheel, and magnetic spul. When vechile press the speed bump, mechanical system start to work, springs that connected to speed bump also connected to shaft by using sling, sling also have driver and it will rotate the flywheel, rotation that gives to flywheel will passed on to rotate generator and produce electricity, to design this mechanical system, each component are determined which strength, stress, velocity, and durability, springs have stress value $248.6 \mathrm{kpsi}$, driven sprocket have diameter $140 \mathrm{~mm}$, driver sprocket have with $50 \mathrm{~mm}$ diameter, breaking strength of chain are $3816 \mathrm{~N}$. And for whole mechanical system are draw by using Auto Cad.
\end{abstract}

Keyword: Mechanical system, generator, speed bump

\section{PENDAHULAN}

Speed bump (polisi tidur) adalah bagian jalan yang ditinggikan yang merupakan tambahan aspal atau semen yang dipasang melintang di jalan sebagai pertanda bagi kendaraan untuk mengurangi kecepatannya . Speed bump dapat melakukan dua fungsi sekaligus, selain sebagai pengaman jalan juga dapat menghasilkan energi listrik dari konsep desain generator, listrik yang dihasilkan dapat dipakai untuk penerangan, ataupun sebagai sumber energi dari palang pintu otomatis, ini juga merupakan konsep ramah lingkungan serta murah untuk implementasinya sendiri. 
Generator listrik adalah perangkat yang mengubah energi mekanik yang Diperoleh dari sumber eksternal menjadi energi listrik sebagai output. Dan hal ini sangat penting untuk memahami bahwa sebuah generator tidak benar-benar menciptakan energi listrik, namun generator menggunakan energi mekanik yang memberikan gaya dan putaran pada pada medan magnet sehingga dapat menghasilkan energi listrik, mekanisme ini juga dapat kita pahami dari generator pompa air yang menyebabkan aliran air namun sebenarnya tidak menciptakan air yang mengalir dan melewatinya. Energi terbarukan ialah energi yang dihasilkan melalui sumber daya alam yang tak terbatas dan dapat diperbarui. Dengan kata lain, karena penggunaan sumber alami, energi ini dapat disimpan dan dapat digunakan terusmenerus. Ada banyak sumber untuk energi terbarukan seperti angin, panas atau cahaya dari matahari, ataupun dari energi potensial air. Energi terbarukan kini menjadi populer untuk penelitian dan pengembangan sekarang. Banyak negara sudah beralih ke energi terbarukan. Selain mencari sumber energi bersih dari sudut pandang lingkungan, mencari sumber energi baru sebagai pengganti bahan bakar fosil juga merupakan faktor utama mengingat berkurangnya persediaaan bahan bakar fosil. Dan ini juga berbanding lurus dengan bertambahnya populasi manusia yang nantinya juga akan meningkatkan permintaan energi yang banyak secara global.

\section{PERANCANGAN ALAT}

Desain alat ini bertujuan untuk memperoleh energi yang dihasilkan akibat adanya beban impuls yang diterima oleh speed bump oleh tabrakan/lindasan roda kendaraan dimana speed bump ini menggerakkan rangkaian sprocket dan rantai diteruskan menuju PMDC.

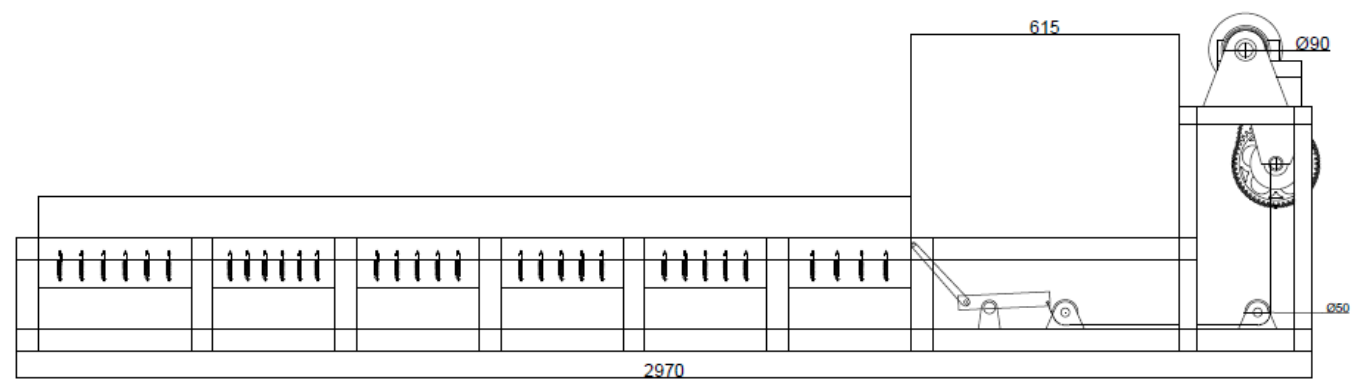



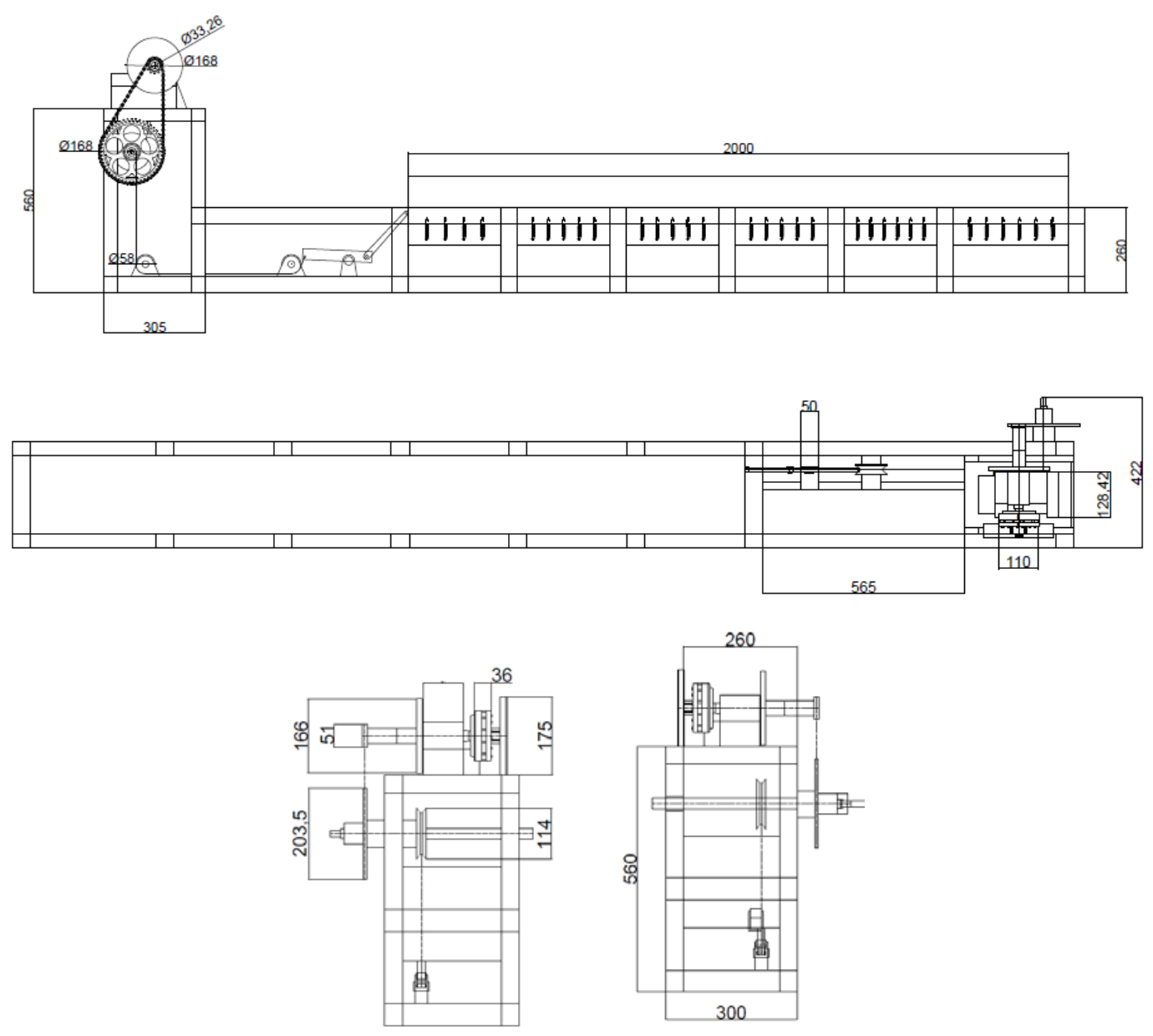

Gambar 1 Alat sistem dalam beberapa pandangan

\section{KOMPONEN YANG DI PAKAI}

\section{a. Pegas}

Perancangan pegas biasanya berhubungan dengan gaya, momen torsi, defleksi dan tegangan yang dialami oleh pegas. Pegas banyak kegunaannya dalam konstruksi mesin, yakni sebagai pengontrol getaran, pada saat penyambungan pegas yang dipasang sebanyak 62 buah pada bagian depan 31 dan bagian belakang 31 buah.

\section{b. Poros}

Poros merupakan salah satu bagian yang terpenting dari setiap mesin. Hampir semua mesin meneruskan tenaga bersama-sama dengan putaran.

\section{c. Bantalan}

Pada perancanaan bantalan ini digunkan bantalan dengan type sigle row angular contack ball bearing, dengan alasan bantalan ini dapat menahan dua jenis beban yaitu jenis beban radial dan jenis beban aksial. 


\section{d. Sprocket}

Rancangan sprocket didesain dan dihitung berdasarkan persamaan rumus garis singgung persekutuan luar lingkaran.

\section{e. Flywheel}

adalah sebuah roda yang dipergunakan untuk meredam perubahan kecepatan putaran dengan cara memanfaatkan kelembaman putaran (moment inersia). Karena sifat kelembamannya ini roda gila dapat menyimpan energi mekanik untuk waktu singkat.

\section{PROSES PRODUKSI SISTEM MEKANIK}

\section{a. Proses Pemotongan}

Proses produksi awal yang dilakukan dalam manufaktur sistem mekanisme speed bump ini adalah pemotongan plat besi dan besi siku menjadi beberapa potongan dengan dimensi tertentu sesuai dengan yang dibutuhkan.

\section{b. Proses Pengelasan}

Dengan mesin las listrik, mengelas potongan-potongan besi siku dengan ukuran tertentu dan merakit sesuai desain yang telah dibuat kemudian untuk mengunci kondisi ini dilakukan pengelasan agar kondisi alat sistem mekanisme ini lebih kokoh.

\section{c. Proses Pembubutan}

Membuat poros yang dibutuhkan sebagai media hantaran putaran dan energi pada saat sistem mekanisme beroperasi dengan menggunakan mesin bubut konvensional dengan ukuran-ukuran yang tepat. Pada poros ini akan dilekatkan bearing dan roda gigi.

\section{d. Proses Polishing}

Polishing atau menghaluskan permukaan sistem mekanisme agar nantinya posisi peletakan speed bump dijamin tidak akan mengalami pergeseran atau diposisi yang akan merugikan. Kerugian yang terjadi akibat disposisi speed bump salah satunya mudah terjadi keretakan speed bump pada permukaan plat terutama bagian yang tidak halus atau rata.

\section{e. Proses Coating dan Painting}

Tujuan dilakukannya pengecatan atau coating adalah menghambat laju korosifitas logam yang terkandung dalam alat sistem mekanisme speed bump, selain itu bertujuan untuk membuat penampilan sistem mekanik menarik, rapi dan expensive. Proses dilakukan dengan bantuan kompresor agar pengecatan lebih maksimal dan ekonomis. 


\section{HASIL}

Perancagan alat ini bertujuan untuk memperoleh energi yang dihasilkan akibat adanya beban impuls yang diterima oleh speed bump dimana speed bump tersebut menggerakkan generator.

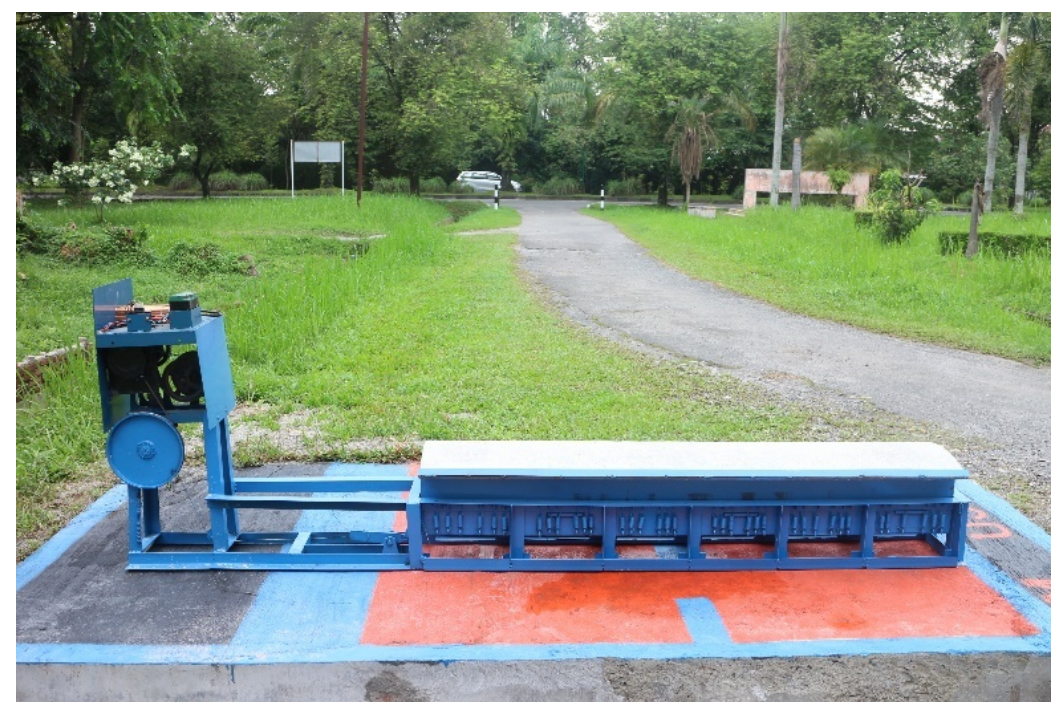

\section{ANALISA GAYA INPUT PADA SISTEM MEKANIK}

Agar dapat meghitung gaya pada setiap komponen sistem mekanik maka harus diketahui dulu gaya input-nya, gaya input dihitung saat kendaraan memberikan gaya ke speed bump, Kemudian tuas akan menarik tali baja yang bersentuhan dengan katrol dan kemudian memberikan putaran terhadap poros yang terpasang sprocket. Untuk menghitung gaya input maka merujuk pada diagram benda bebas (FBD) untuk mendapat gaya input sesuai dengan yang diharapkan.

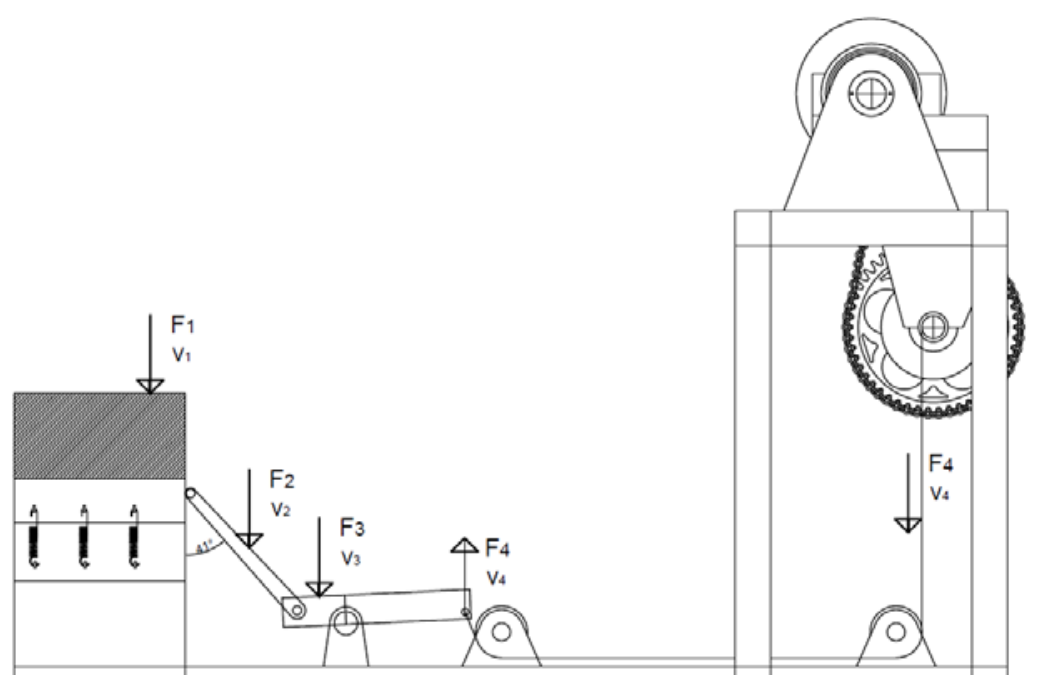


Sebelum mengolah lebih lanjut, beberapa data tidak dapat diukur kuantias dan kualitasnya akibat ketidaksiapan peralatan pengujian untuk infromasi tersebut, maka dapat dilakukan asumsi sebagai berikut:

1. Kekuatan pegas diabaikan

2. Gaya gesek diabaikan

Diketahui :

$m=1375 \mathrm{~kg}$

$g=9,81 \frac{\mathrm{m}}{\mathrm{s}}$

$l k=7 \times 10^{-2} \mathrm{~m}$

$l b=14 \times 10^{-2} \mathrm{~m}$

$x=9 \times 10^{-2} \mathrm{~m}$

$Z_{A}=48$ mata

$Z_{B}=12$ mata

$t=1 s$

Pertama mencari gaya yang dihasilkan oleh kendaran sesaat setelah melintas sistem mekanik dengan rumus Hukum Newton II.Free body diagram untuk $\mathrm{F}_{1}$

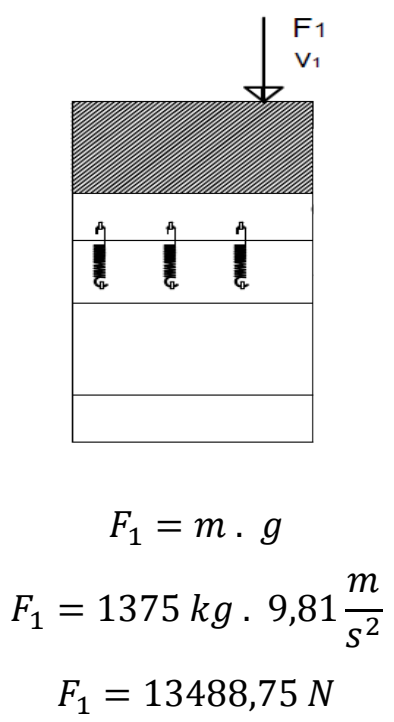

Setelah $\mathrm{F}_{1}$ diperoleh kemudian dapat menghitung $\mathrm{F}_{2}$ dengan menggunakan aturan trigonometri.Free body diagram untuk $\mathrm{F}_{2}$ 


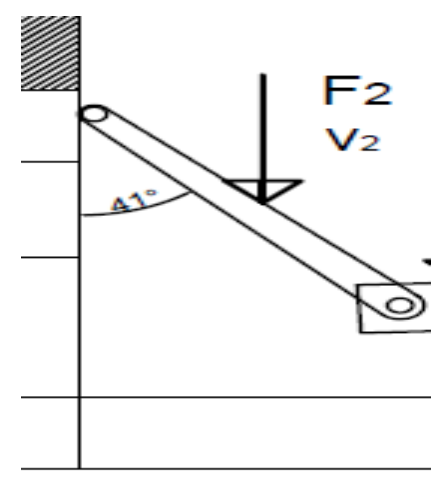

$$
\begin{gathered}
F_{2}=13488,75 \cos 41^{\circ} \\
F_{2}=13488,75 \cdot 0,7574 \\
F_{2}=10179,95 \mathrm{~N} \\
F_{2}=F_{1} \cos \theta
\end{gathered}
$$

Kembali kita menggunakan rumusan trigonometri untuk mencari $F_{3}$ dengan menggunakan data $\mathrm{F}_{2}$. Free body diagram untuk $\mathrm{F}_{3}$

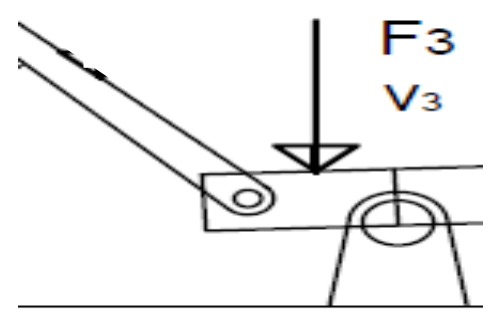

Selanjutnya untuk memperoleh $\mathrm{F}_{4}$ menggunakan rumusan momen gaya karena berhubungan dengan pesawat sederhana jungkat-jungkit.

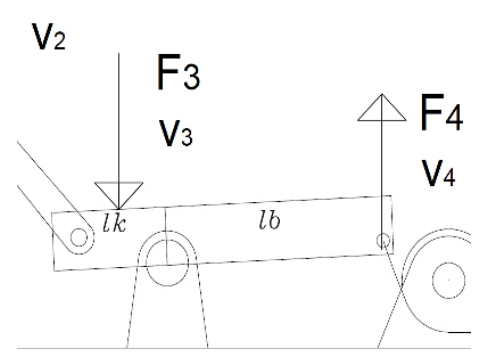




$$
\begin{gathered}
\Sigma M=0 \\
F_{3} \cdot l k=F_{4} \cdot l b \\
7682,91.7 \times 10^{-2}=F_{4} \cdot 14 \times 10^{-2} \\
F_{4}=3841,455 \mathrm{~N}
\end{gathered}
$$

Untuk menghitung berapa panjang kawat baja yang terangkat/tertarik menggunakan rumusan matematika bidang sebangun.

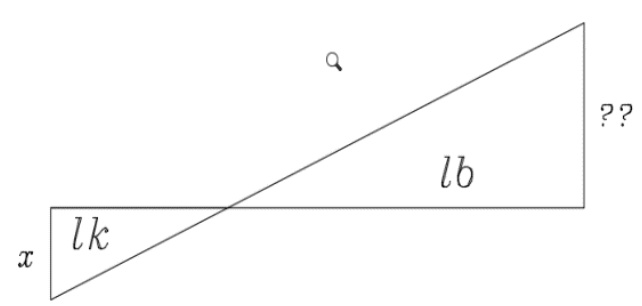

$$
\begin{gathered}
p=\frac{l b \cdot x}{l k} \\
p=\frac{14 \times 10^{-2} \cdot 9 \times 10^{-2}}{7 \times 10^{-2}} \\
p=18 \times 10^{-2} \mathrm{~m}
\end{gathered}
$$

Menghitung keliling poros A menggunakan rumusan matematika keliling lingkaran.

$$
\begin{gathered}
k=3,14 \cdot 2,5 \times 10^{-2} \\
k=7,85 \times 10^{-2} \mathrm{~m} \\
k=\pi \cdot d
\end{gathered}
$$

Setelah memperoleh data panjang kawat dan keliling poros A kemudian menghitung kecepatan sudut dari poros melalui rumusan periode dan kecepatan sudut.

$$
\begin{gathered}
T=\frac{k}{p}=\frac{7,85 \times 10^{-2}}{18 \times 10^{-2}} \\
T=0,4361 \mathrm{~s} \\
\omega=2 \cdot \pi \cdot \frac{1}{0,4361 \mathrm{~s}} \\
\omega=4,586 \pi \frac{\mathrm{rad}}{\mathrm{s}}
\end{gathered}
$$




$$
\begin{gathered}
\omega=2 \pi \cdot \frac{1}{T} \\
v=4,586 \pi \frac{\mathrm{rad}}{\mathrm{s}} \cdot \frac{2,5 \times 10^{-2}}{2} \mathrm{~m} \\
v=0,36 \frac{\mathrm{m}}{\mathrm{s}} \\
v=\omega \cdot r
\end{gathered}
$$

Maka dengan data yang telah dihitung dapat diperoleh banyaknya putaran pada poros B

$$
\begin{gathered}
\frac{\omega \cdot t}{2 \pi} \frac{12}{N_{B}}=\frac{12}{48} \\
\omega_{B}=\frac{2 \pi N_{B}}{t} \\
\omega_{B}=\frac{2.9,172 \mathrm{rad} \cdot \pi}{1 \mathrm{~s}} \\
\omega_{B}=18,344 \pi \frac{\mathrm{rad}}{\mathrm{s}} \\
\frac{4,586 \pi \frac{\mathrm{rad}}{\mathrm{s}} \cdot 1 \mathrm{~s}}{2 \pi}=\frac{1}{4} \\
N_{B} \\
N_{B}=9,172 \mathrm{rad}
\end{gathered}
$$

Selanjutnya kita harus menghitung torsi yang dihasilkan oleh sistem mekanik dengan menggunakan data yang telah diperoleh sebelumnya. menghitung torsi yang dihasilkan system menggunakan rumusan torsi dan lengan.

$$
\begin{gathered}
\mathrm{T}=F_{4} \cdot r \\
\mathrm{~T}=3841,455 N \cdot 2,5 \times 10^{-2} m \\
\mathrm{~T}=96,03 N
\end{gathered}
$$

Untuk menghitung daya yang diperoleh oleh sistem mekanik menggunakan persamaan sebagai berikut:

$$
\begin{gathered}
\boldsymbol{P}=\boldsymbol{\tau} \cdot \boldsymbol{\omega}_{\boldsymbol{B}} \\
P=96,03 \mathrm{Nm} \cdot 18,344 \pi \frac{\mathrm{rad}}{\mathrm{s}} \\
P=96,03 \cdot 0,16 \\
\boldsymbol{P}=\mathbf{1 5}, \mathbf{3 6 4 8} \boldsymbol{w a t t}
\end{gathered}
$$

Daya yang didapat setelah perhitungan daya, dengan menggunakan mobil honda freed dengan massa $1375 \mathrm{Kg}$ didapatkan daya sebesar 15,35648 watt, namun pengujian juga dilakukan dengan menggunakan mobil CR-V maka didapat data sebagai berikut.

Tabel 4.1 Data hasil perhitungan daya yang diperoleh secara teoritis 


\begin{tabular}{|c|c|c|c|c|}
\hline \multirow{2}{*}{ Percobaan } & \multicolumn{2}{|c|}{ Putaran (rpm) } & \multicolumn{2}{c|}{ Daya (watt) } \\
\cline { 2 - 5 } & HondaFreed & Honda CR-V & HondaFreed & Honda CR-V \\
\hline I & 880 & 1100 & 15,3648 & 17,55 \\
\hline V $=5 \mathrm{~km} / \mathrm{h}$ & 666 & 888 & 19,026 & 21,8052 \\
V $=8 \mathrm{~km} / \mathrm{h}$ & 884 & 1110 & 30,7296 & 35,1136 \\
\hline III & & & & \\
\hline
\end{tabular}

\section{KESIMPULAN}

Dimensi Perancangan Alat Pembangkit Daya adalah Sebagai berikut:

1. Dimensi Perancangan Alat Pembangkit Daya adalah Sebagai berikut:

a) Putaran input awal pada sprocket adalah $1110 \mathrm{rpm}$

b) Sprocket yang digunakan memiliki diameter

1. Sprocket $1: 140 \mathrm{~mm}$

2. Sprocket $2: 50 \mathrm{~mm}$

c) Bantalan yang digunakan ialah tipe single row angular contact ball bearing

d) Rantai yang dihitung dengan hasil sebagai berikut: adalah

Dengan spesifikasi

Pitch: $6 \mathrm{~mm}$

Roll Diameter: $4 \mathrm{~mm}$

Pin Diameter: 2 mm

Velocity Ratio : 277 rpm

Average velocity : $1,332 \mathrm{~m} / \mathrm{s}$

Kekuatan putus rantai : $3816 \mathrm{~N}$

e) Nilai Tegangan pegas yang digunakan adalah $1,543 \mathrm{~N} / \mathrm{mm}^{2}$ serta tegangan pegas Torsi Sebesar $9081,291 \mathrm{~N} / \mathrm{mm}^{2}$

f) Nilai momen alternatif sebesar $3,607 \mathrm{~N} / \mathrm{mm}^{2}$ dan tegangan puntir midrange sebesar $0,05196 \mathrm{~N} / \mathrm{mm}^{2}$

g) Flywheel menyimpan energi sebesar 326,20 Joule

2. Hasil analisa gaya pada sistem mekanik secara keseluruhan yang dimulai dari pada saat mobil memberikan gaya adalah gaya pada penampang speed bump (F1) adalah 13488,75 N lalu 
pada tuas beban (F2) adalah sebesar 10179,95 N, lalu untuk tuas yang bekerja (F3) dengan sistem pesawat sederhana dibagi menjadi dua lengan $\mathrm{lk}$ dan $\mathrm{lb}$ maka untuk beban F3 dengan lengan kuasa adalah 7682,91 $\mathrm{N}$ dan gaya terhadap lengan beban (F4) adalah $3841 \mathrm{~N} / \mathrm{m}$, panjang kawat baja yang digunakan ialah $18 \times 10^{-2} \mathrm{~m}$, pada poros A memiliki kecepatan sudut $4,586 \pi \frac{\mathrm{rad}}{\mathrm{s}}$, pada poros B $18,344 \pi \frac{\mathrm{rad}}{\mathrm{s}}$, torsi yang didapat pada sistem mekanik adalah 96,03 N daya yang didapat adalah 15,3648 Watt.

\section{SARAN}

1. Pada saat saat pembuatan alat sistem pembangkit daya ini voltase yang dihasilkan dapat lebih ditingkatkan dengan mengganti kuat medan magnet, menambahkan rasio putaran sprocket, menambah jumlah lilitan kawat pada generator.

2. Studi Literatur Sangt penting dilakukan dalam melakukan penelitian.

3. Pengembangan penelitian dengan menggunakan logam yang lebih ringan namun kuat sehingga sistem mekanik speedbumo dapat dipindahkan. 